\title{
A diversidade étnico-racial sob o olhar docente e discente: uma abordagem reflexiva e colaborativa
}

Racial ethnic diversity under the teaching and student look: a reflective and collaborative approach

Kárita Carlos de Souza Fell

Graduada em Letras pela UNEMAT, Campus Luciara Professora na Rede Estadual de Ensino (SEDUC/MT).

E-mail: karitaenglishteacher@gmail.com

\author{
Célia Ferreira de Sousa \\ Mestra em Letras pela UNEMAT Cáceres \\ Professora IFMT Campus Confresa. \\ E-mail: celia.sousa@cfs.ifmt.edu.br
}

\begin{abstract}
Resumo: Este texto relata uma experiência realizada sobre a diversidade étnico-racial envolvendo professores e os estudantes do $2^{\circ}$ ciclo $>6^{\circ}$ ano, turma "A" da Escola Estadual Teotônio Carlos da Cunha Neto. Os instrumentos para a coleta dos dados foram recursos audiovisuais e entrevista com roteiro de questões semiestruturadas aplicados no ano letivo de 2015. A sala de aula foi tomada como um laboratório de estudos e análises tendo como foco a temática das relações étnico-raciais. O aporte teórico contemplou estudos de autores como: Munanga (2005), Ferreira (2013), Santos (2008) e outros que discutem a temática e ainda a Lei 10.639/2003. Os resultados mostraram que a melhor maneira para se trabalhar o respeito a diversidade étnico-racial é através das escolas. Neste trabalho é primordial o conhecimento por parte dos educadores, dinamicidade, ludicidade, bem como abordagens atrativas, reflexivas e enriquecedoras de conhecimentos aos estudantes, pois serão estes estudantes frutos do trabalho escolar, que irá combater ou, caso contrário, reproduzir as desigualdades sociais
\end{abstract}

Palavras-chave: Diversidade étnico-racial. História e Cultura Afro-Brasileira. Racismo e preconceito.

\begin{abstract}
This paper reports an experience of ethnic-racial diversity involving teachers and students of the 2nd> 6th grade, class "A" of Teotônio Carlos da Cunha Neto State School. The instruments for data collection were audiovisual resources and interview with script of semi-structured questions applied in the school year of 2015. The classroom was taken as a study and analysis laboratory focusing on the theme of ethnic-racial relations. The theoretical contribution included studies by authors such as Munanga (2005), Ferreira (2013), Santos (2008) and others who discuss the theme and Law 10.639/2003. The results showed that the best way to work respecting ethnic-racial diversity is through schools. In this work it is paramount the knowledge on the part of the educators, dynamics, playfulness, as well as attractive, reflective and knowledge enriching approaches to the students, because these students will be fruits of the school work, that will fight or, otherwise, reproduce the social inequalities.
\end{abstract}

Keywords: Ethnic - Racial Diversity. Afro-Brazilian History and Culture. Racism and prejudice. 


\section{Introdução}

Sendo professora da Educação Básica do Estado de Mato Grosso lotada na EE Teotônio Carlos da Cunha Neto durante os anos de 2014, 2015, 2016 e 2017, tive a oportunidade de abordar nas aulas ministradas e materializar o resultado final em vídeo sobre a temática - Diversidade, com foco nas questões étnico-raciais e em concordância com o Projeto - África: Currículo de todos nós?, instituído na unidade escolar. Tendo como amparo legal e incentivo a Lei 10.639/2003, a qual torna obrigatório às Redes de Ensino trabalhar em sala de aula as questões étnico-raciais com a temática da História e Cultura Afro-Brasileira.

Muito além disso é necessário que a escola aborde no currículo a diversidade étnicoracial, não somente pelo fato de ainda presenciarmos situações de preconceito contra os afrodescendentes em vários setores da sociedade, mas sim, "lutar contra uma das mais perversas formas de violência perpetradas cotidianamente na sociedade brasileira", conforme afirma Munanga (2005).

Trabalhar a história do continente africano e dos africanos, a luta dos negros no Brasil, a cultura negra brasileira e o negro na formação da sociedade nacional brasileira como conteúdos componentes do currículo escolar contribuem fundamentalmente para a compreensão desses fenômenos, tendo o conhecimento como ferramenta imprescindível para a redução dos pré-conceitos acerca da diversidade étnico-racial existente em nosso país.

Destarte, o cerne desta pesquisa foi a diversidade étnico-racial que a partir de um trabalho pedagógico desenvolvido em 2015 com os estudantes do $2^{\circ}$ ciclo $>6^{\circ}$ ano, turma "A" da Escola Estadual Teotônio Carlos da Cunha Neto, resultou em uma entrevista gravada em áudio e vídeo com dois professores afrodescendentes da rede estadual de ensino em Confresa, feita pelos estudantes com o acompanhamento da professora regente e coordenação pedagógica.

Os instrumentos para a coleta dos dados foram recursos audiovisuais e entrevista com roteiro de questões semiestruturadas aplicados no ano letivo de 2015. A entrevista, segundo Gil (2002, p. 109) pode ser definida como "a técnica em que o investigador se apresenta frente ao investigado e lhe formula perguntas, com o objetivo de obtenção dos dados que interessam à investigação", ou seja, ainda para Gil (2002) “a entrevista é, portanto, uma 
forma de investigação social. Mais especificamente, é uma forma de diálogo assimétrico, em que uma das partes busca coletar dados e a outra se apresenta como fonte de informação".

Para a realização da entrevista que aconteceu logo após aulas teóricas em sala de aula sobre a escravidão no Brasil, onde foi elaborado um roteiro de questões semiestruturadas para serem aplicadas junto aos entrevistados, sendo um total de treze questões. No decorrer da entrevista que ocorreu na unidade escolar e em contra turno, cada estudante teve a oportunidade de efetivar uma das perguntas aos entrevistados.

No roteiro de questões constavam 13 perguntas: 1 - Atualmente percebe-se que os negros têm ocupado papéis importantes na sociedade brasileira, como por exemplo, na política, na educação, na saúde e várias outras áreas. Como você avalia esse papel importante que o negro tem desempenhado na sociedade no século XXI? 2 - Você já sofreu ou sofre preconceito pela cor da sua pele? 3 - Você se acha diferente dos outros pelo fato de ser uma pessoa negra? 4 - É notável que em pleno século XXI ainda existe preconceito contra o negro, como você se sente diante de tal desrespeito? 5 - Você já se sentiu desprezada por ser negra (o)? 6 - Qual a sua visão em relação as atitudes de pessoas preconceituosas? 7 Como você reage quando se depara com alguém que age com preconceito contra os outros. 8 - Você já foi chamado (a) de negro em tom de preconceito? 9-Quando você era estudante, você já sofreu bullying por causa da sua cor? E no seu ambiente de trabalho? 10 - O Brasil é um país que ainda mostra traços de desigualdades social e racial. Enquanto uma minoria possui maior parte da renda nacional, outros vivem na pobreza. Grande parte destas pessoas que vivem na pobreza, são negros, frutos do passado histórico do Brasil. Quais são suas explanações sobre o racismo no mercado de trabalho? 11 - Comenta-se que os negros em sua maioria têm mais dificuldades de ingressar em um curso superior ou mesmo de permanecer na escola e concluir o Ensino Fundamental e Médio. Você é a favor das cotas raciais nas universidades e em concursos públicos? 12 - Enquanto professores da educação básica, o que vocês têm feito para combater o racismo? 13 - Por fim, como vocês querem que o negro seja representado na sociedade?

Diante dos dados obtidos, através das perguntas, analisamos, sistematizamos e discutimos à luz de teorias que tratam sobre questões étnico-raciais, além de poder socializar de forma mais ampla os resultados alcançados a partir da realização tanto da entrevista, quanto das demais atividades realizadas em sala de aula em consonância com o Projeto: “África: Currículo de todos nós?”. 
Utilizamo-nos da pesquisa de natureza qualitativa, que conforme Menga Ludke e Marli André (1986, p. 44), "tem o ambiente natural como sua fonte direta de dados e o pesquisador como seu principal instrumento". Ainda para as mesmas autoras (1986, p. 44), "a preocupação com o processo é maior do que com o produto".

Apropriamos da leitura de bibliografias impressas e digitais e também da pesquisa de campo, visando o aprofundamento de conhecimentos relacionados à temática em evidência. Para Gil (2002, p. 44) a pesquisa bibliográfica é aquela em que "é desenvolvida com base em material já elaborado, constituído principalmente de livros e artigos científicos". E a pesquisa de campo, "é aquela utilizada com o objetivo de conseguir informações e/ou conhecimentos acerca de um problema, para o qual se procura uma resposta, ou de uma hipótese, que se queira comprovar, ou, ainda, descobrir novos fenômenos ou as relações entre eles" (Lakatos, 2003, p. 186).

Os sujeitos entrevistados e colaboradores da pesquisa foram dois professores afrodescendentes (sendo um do sexo feminino e outro do sexo masculino). Na época, ela, lotada na Escola Estadual 29 de Julho e, ele, na Escola Estadual Teotônio Carlos da Cunha Neto, os quais são aludidos nesse texto como entrevistado A e entrevistado B.

Durante o processo de pesquisa, os estudantes foram atores essenciais e atuaram de forma significativa. Após o trabalho pedagógico desenvolvido em sala de aula no intuito de que os estudantes pudessem ter uma visão mais ampla sobre as características étnicoculturais, sociais, políticas e econômicas, dos vários olhares que tem sobre o continente africano e as relações étnico-raciais na sociedade brasileira, os próprios estudantes com auxílio da professora elaboraram o roteiro de questões semiestruturadas para proceder a entrevista. Além disto, também tiveram a oportunidade de atuarem como entrevistadores de modo colaborativo.

Conclusa a entrevista e de posse dos resultados materiais obtidos, foi possível socializar com os estudantes da turma trabalhada, bem como em culminância do Projeto África: Currículo de todos nós? com toda a comunidade escolar o resultado final, inclusive, servindo o produto como material pedagógico para ser explorado na educação quando se tratar de estudos voltados à diversidade.

Contudo, o material obtido é rico em descrição de situações e acontecimentos. E a seguir mostramos dados da entrevista analisada, tendo como subsídio o diálogo com autores que tratam sobre a temática para confirmar ou esclarecer pontos de vistas dos entrevistados.

\section{A diversidade étnico-racial: conceitos e práticas}


Discutir o tema diversidade é algo muito importante no contexto escolar dado a sua amplitude e a necessidade de conhecimento por parte dos estudantes, embora gere muitas polêmicas devido as várias vertentes sobre o assunto. Nota-se que essa temática tem sido objeto de debates entre vários estudiosos, bem como solicitação por todos em relação ao respeito às diferenças, físicas, psicológicas, religiosas, sexuais e de raças as quais devem ser respeitadas por todos os cidadãos.

Sobre essa questão, Ferreira (2013), afirma que,

no Brasil, as principais formas de preconceitos foram e são geradas pelas desigualdades e pelo desrespeito às diferenças, especialmente no que tange às questões étnico-raciais, de gênero, de orientação sexual e geracionais, tanto com relação às crianças e aos adolescentes como aos idosos, de territorialidade, de deficiência nas suas mais diversas expressões, e por razões socioeconômicas, (FERREIRA, 2013, p. 55).

Analisando esse excerto, apreendemos que as atitudes preconceituosas são múltiplas e ocorrem de diversas formas e em diversos lugares da sociedade. Por mais que há leis que garantem o direito e o respeito a diversidade, grande parcela da sociedade desconhece e pratica atos desrespeitosos contra o próximo, às vezes, mesmo sem saber se as ações ou palavras proferidas contrariam a dignidade humana causando assim, graves consequências, sendo a escola um dos espaços em que se nota acentuadamente ações preconceituosas.

Embora a igualdade formal de direitos esteja assegurada juridicamente pela Constituição Brasileira, existe uma distância enorme entre o que está posto e o que ocorre na prática. Para Munanga (2005), não existem leis no mundo que sejam capazes de erradicar as atitudes preconceituosas existentes nas cabeças das pessoas, atitudes essas provenientes dos sistemas culturais de todas as sociedades humanas.

Nessa mesma vertente, afirma Ferreira (2013), "Uma das dificuldades no combate às desigualdades e o desrespeito às diferenças é o desconhecimento dos condicionamentos histórico-sociais para que se possa "desnaturalizar" o quadro atual, ou seja, a falta de compreensão da construção dos preconceitos, das discriminações, das diferenciações identitárias, entre outros (FERREIRA, 2013, p. 54)".

Diante dessas considerações, e fazendo uma analogia ao que ocorre no ambiente escolar, notamos diariamente que atitudes preconceituosas entre os estudantes são praticadas mesmo sem eles compreenderem que determinadas ações ou palavras são formas de desrespeito à diversidade que há no ambiente escolar, como exemplos podemos citar, os apelidos pejorativos; xingamentos, agressões verbais e/ou físicas; exclusão de colega em 
trabalhos em grupos pela cor da pele; com menor poder aquisitivo ou com necessidade educacional especial e assim por diante.

Sobre essa diversidade no contexto escolar, uma das vertentes relevantes a ser considerada é a miscigenação do povo brasileiro, esse é resultado de uma mistura de vários povos, a exemplo, dos indígenas, europeus e africanos.

Portanto, enquanto professores e mediadores da aprendizagem desprovida de preconceito, estigma e exclusão, não podemos deixar de lado à abordagem na escola sobre esta diversidade, uma vez que precisamos acreditar que por mais simples que sejam os enfoques sobre o assunto é um ponto de partida para transformações conceituais, sociais e boas práticas dos cidadãos em sociedade.

Assim sendo, e para avigorar ainda mais o assunto, Santos (2008) afirma que a escola,

é responsável por trabalhar no sentido de promover a inclusão e a cidadania de todos os alunos, visando a eliminar todo tipo de injustiça e discriminação, enxergando os seres humanos dotados de capacidades e valorizando-os como pessoas, principalmente dos afrodescendentes, marcados por um histórico triste na educação e na sociedade brasileira de discriminação, racismo e preconceito (SANTOS, 2008, p. 30).

Isso demonstra que a escola deve estar comprometida no combate de qualquer que seja o preconceito. É um espaço onde necessita considerar todos os tipos de distinção, respeitar e valorizar as pessoas, independentemente, da raça, cor, sexo, religião, condição física ou psicológica, pois cada ser humano tem suas características e capacidades específicas.

Corroborando com esta reflexão, Santos (2008) afirma que,

os afrodescendentes devem ser reconhecidos em nossa sociedade com as mesmas igualdades de oportunidades que são concedidas a outras etnias e grupos sociais, buscando eliminar todas as formas de desigualdades raciais e resgatar a contribuição dos negros na formação da sociedade brasileira e, assim, valorizar a história e cultura dos afro-brasileiros e africanos (SANTOS, 2008, p. 30).

No Brasil, a história da população negra é mais conhecida pela sua condição de escravos nos séculos passados. A escravidão na literatura teórica, a princípio foi documentada de modo que o negro na esfera econômica é tido como mercadoria, na esfera cultural como exótico e, na política como um grupo sem capacidade de organização e proposição (BRASIL, 2008). 
Como se sabe, mesmo após o fim da escravidão no Brasil os ex-escravos ou os afrodescendentes não conseguiram se precaver da discriminação racial e das consequências desta, como por exemplo, a exclusão social e a miséria.

A discriminação racial que estava subsumida na escravidão emerge, após a abolição, transpondo-se ao primeiro plano de opressão contra os negros. Mais do que isso, ela passou a ser um dos determinantes do destino social, econômico, político e cultural dos afrobrasileiros (HASENBALG, 1979; SANTOS, 1997 Apud BRASIL, 2005, p. 21).

Deixados à própria sorte e diante das mazelas produzidas pela sociedade não negra aos afrodescendentes, os mesmos se viram com a necessidade de mudar esse cenário. Assim, a valorização da educação formal foi tida como uma das técnicas sociais no intuito de superar a condição de excluídos da sociedade e de miseráveis. "A valorização da educação formal foi uma das várias técnicas sociais empregadas pelos negros para ascender de status" (BRASIL, 2005, p. 21), tornando, assim, a escola como um meio de promoção social.

Neste percurso, foi renegado aos negros o direito a uma educação em condições de igualdade com os demais, permanecendo a educação na vida de muitos deles como objeto de desejo, pois várias questões, entre elas habitacionais e locacionais, não permitiam o acesso à educação formal, ou quando a tinham eram em condições precárias tendo como fruto resultados aborrecíveis na aprendizagem.

Diante destas dificuldades, nota-se que os negros através de seus movimentos, denominados "movimentos negros" e outros, empreenderam uma luta no sentido de autorreconhecimento como seres humanos e não apenas como mercadorias ou objeto de trocas, mas como uma população portadora de cultura que deve ser reconhecida, portadora de direitos, entre eles, o da educação formal que deve ser garantida com qualidade de acesso e permanência.

Nesta questão histórica de sofrimento e luta muitas coisas há de se considerar positivas, entre elas a promulgação em 2003, da Lei n. 10.639. A referida Lei caracteriza-se como um marco importantíssimo na vida dos afrodescendentes no Brasil, pois foi proclamada com o objetivo de promover a valorização e o reconhecimento da diversidade étnico-racial na educação brasileira.

\section{Desigualdades sociais, raciais e oportunidades: considerações dos entrevistados}

Ser negro é ser diferente dos outros? De maneira nenhuma! Porque a diferença está no preconceito. A cor da pele não me restringe de nada, 
não me impede de fazer nada que uma pessoa branca, uma pessoa parda como o IBGE trata faz. Então eu não me sinto diferente, mas com certeza nós ainda somos tratados de maneiras diferentes em várias situações por sermos negros (Entrevistado A, 2015).

Apresentamos os dados obtidos na pesquisa em forma de excertos, as apreciações dos mesmos em diálogo com autores que amparam as discussões, bem como as nossas reflexões. Subsidiamos nossa discussão teórica em leis, autores, tais como Munanga (2005), além de outros que estudam a temática.

Embora utilizamos treze questões para a coleta dos dados, a seguir organizamos apenas quatro blocos de discussões de modo a contemplar as contribuições dos entrevistados.

\subsection{O negro no século XXI: algumas considerações sobre seus sonhos e realidade}

Os negros no Brasil são frutos de um passado histórico marcado por muitas lutas no que diz respeito às questões de desigualdades raciais e sociais, mas aos poucos os negros vêm ascendendo em vários setores da sociedade. Claro, ainda não como o desejado, mas a distância entre o sonhado e o real não é mais a mesma se comparada aos séculos anteriores.

Sabe-se que, como direito social a educação aos negros não será a salvação e/ou reparação de todos os males causados a população negra, no entanto, também ela é considerada uma das vias de acesso primordial aos vários direitos que eles têm.

A partir do desembarque dos negros no Brasil nota-se que o papel desempenhado pelos mesmos na sociedade brasileira era o de escravos nas grandes lavouras de cana - de açúcar e em vários outros ramos econômicos garantindo, por exemplo, aos senhores de engenhos e aos latifundiários grandes patrimônios. Enquanto isso, viviam em condições precárias. Isto, despertou nos mesmos a criação de estratégias para se libertarem do cenário escravista e serem portadores dos mesmos direitos que os não negros usufruíam.

Situação expressa com clareza na voz de um dos entrevistados: "Todas as conquistas que o negro está alcançando nesse século XXI é resultado de muito trabalho. Muitas pessoas já sofreram, muitas pessoas até mesmo perderam as suas vidas na luta pelo reconhecimento para que o negro tenha o seu lugar visibilizado" (Entrevistado A, 2015).

Tendo essas reflexões como ponto de partida para a discussão percebemos o quão doloroso foi para que na atualidade os negros tivessem espaço na sociedade, mas, mesmo após a abolição da escravidão no Brasil através da Lei Áurea de 1888 é possível constatar 
na literatura que a lei não foi o suficiente para que uma série de problemas fossem resolvidos, decorrentes das ações discriminatórias ao longo dos anos de escravidão.

Na verdade, não só nesse caso, mas também em outros, a existência de uma lei nesse país nunca foi o suficiente para que se cumprissem o prescrito nela, permanece a luta pela participação justa de negros e negras nos mais diversos ambientes da sociedade brasileira e pelo respeito à humanidade dessas mulheres e homens produtores de cultura desse país.

Ao considerar que o papel desempenhado socialmente pela população negra no século XXI não se difere muito do contexto de séculos passados, embora tenha tido avanços significativos, um dos entrevistados considera que ainda não está como o desejado, e corrobora que

nós deveríamos estar ocupando vários outros lugares [na sociedade], mas nós sabemos que pra você alcançar uma vaga no concurso, pra você ocupar um lugar de destaque na política você precisa acima de tudo que estudar. O primeiro passo pro negro, pro branco, para o índio alcançar um lugar de destaque na sociedade é através do estudo, (Entrevistado A, 2015).

É possível depreender na fala do entrevistado "A" a sinalização ainda que tímida, do reconhecimento que a população negra já ocupa vários espaços na sociedade, entretanto, deveria estar ocupando vários outros lugares. Admite-se também que uma das formas de acesso aos vários papéis desempenhados na sociedade é por meio dos estudos. Estudar se constitui fator essencial na vida de qualquer cidadão. Assim, todos necessitam passar pelos espaços escolares, mesmo sendo nesses, onde nos deparamos com diversas formas de preconceito e discriminação racial e a perpetuação de atitudes preconceituosas.

Mesmo que a educação, no Brasil, seja um direito constitucional conforme o artigo 205 da Constituição Federal (1988). Gomes (2007) afirma que: Porém, todas as pesquisas oficiais realizadas nos últimos anos apontam como o campo educacional tem produzido e reproduzido no seu interior um quadro de desigualdades raciais.

Neste cenário entristecedor, todos os atores educacionais devem ter compromisso e o preparo necessário para lidar com situações problemáticas de convivência com a diversidade existente no contexto escolar, bem como com as manifestações discriminatórias enfrentadas no dia a dia por qualquer sujeito que ali esteja. Caso contrário, "a de considerar como reflexo do nosso mito de democracia racial, [comprometendo], sem dúvida, o objetivo fundamental da nossa missão no processo de formação dos futuros cidadãos responsáveis pelo amanhã, (Munanga, 2005)". 
Passamos a outro bloco de discussão que contempla os saberes dos entrevistados se há preconceito na sociedade devido a cor da pele.

\subsection{O preconceito pela cor da pele: contextos e reflexões}

Preconceito é um juízo pré-concebido, que se manifesta numa atitude discriminatória perante pessoas, crenças, sentimentos e tendências de comportamento. É resultado da falta de saber das pessoas que se prendem às suas ideias pré-concebidas, desprezando outros pontos de vista, por exemplo, (Dicionário Online de Português).

Estudos mostram que no Brasil existem diferentes manifestações e tipos de preconceito. E que as formas mais corriqueiras são preconceito social, racial e sexual.

A ONU ${ }^{1}$ em referência ao massacre ocorrido em 21 de março de 1960 no bairro de Sharpeville, na cidade de Johanesburgo, na África do Sul, estabeleceu o dia 21 de março, como o Dia Internacional de Luta pela Eliminação da Discriminação Racial.

No contexto histórico sobre a luta pela proibição da discriminação racial no Brasil, sabemos que a própria Constituição Federal, de 1988, classificou a prática do racismo como crime. De acordo com o artigo $5^{\circ}$, inciso XLII:

Todos são iguais perante a lei, sem distinção de qualquer natureza, garantindo-se aos brasileiros e aos estrangeiros residentes no país a inviolabilidade do direito à vida, à liberdade, à igualdade, à segurança e à propriedade, nos termos seguintes: a prática do racismo constituiu-se crime inafiançável e imprescritível, sujeito à pena de reclusão de nos termos da lei.

Além da Constituição, a Lei n. 7.716/1989 - que Define os crimes resultantes de preconceito de raça ou de cor; considera crime inafiançável e não prescreve, ou seja, quem cometeu o ato racista pode ser condenado mesmo anos depois do crime.

Importante destacar que a lei supracitada foi alterada pela Lei $\mathrm{n}^{\circ} 12.735$, de 2012, em seus artigos: " 1 o - Serão punidos, os crimes resultantes de discriminação ou preconceito de raça, cor, etnia, religião ou procedência nacional”. "20 - Praticar, induzir ou incitar a discriminação ou preconceito de raça, cor, etnia, religião ou procedência nacional”.

Como vimos, nos referidos artigos foram acrescidas mais informações, sendo considerado crime, preconceito sobre etnia, religião ou procedência nacional.

\footnotetext{
${ }^{1}$ A Organização das Nações Unidas, também conhecida pela sigla ONU, é uma organização internacional formada por países que se reuniram voluntariamente para trabalhar pela paz e o desenvolvimento mundiais (https://nacoesunidas.org.) 
Nessa perspectiva, e na tentativa de reparar tamanhas desigualdades em relação aos negros no Brasil, em 2014 pelo Congresso Nacional, entrou em vigor a lei n 12.990/2014, que prevê a reserva de $20 \%$ das vagas em concursos públicos aos candidatos que se autodeclarem de cor preta ou parda. Como podemos verificar em seu $1^{\circ}$ artigo:

Art. $1^{\circ}$ Ficam reservadas aos negros $20 \%$ (vinte por cento) das vagas oferecidas nos concursos públicos para provimento de cargos efetivos e empregos públicos no âmbito d a administração pública federal, das autarquias, das fundações públicas, das empresas públicas e das sociedades de economia mista controladas pela União.

Tudo isso foi suficiente para erradicar atitudes preconceituosas no país? Não. A luta por visibilidade e por eliminação de práticas preconceituosas ainda continua até os tempos atuais. As leis existem, mas as práticas de racismo e também a falta de oportunidades de trabalho para negros no Brasil também ainda permanecem fortemente.

Vejamos o que disseram os entrevistados a respeito do questionamento: Se existem preconceitos devido a cor da pele. "Explicitamente não! Claro que a gente tem por outros ângulos, né. Vão te excluindo de algumas situações, mas assim claramente nunca houve situação em que eu tenha sido barrado pela cor da minha pele, mas isto é muito constante na nossa sociedade, (Entrevistado B, 2015).

Pode até ser que o entrevistado B não tenha sofrido preconceito explicitamente pela cor da sua pele. Afirma que tem por outros ângulos, no entanto, não os menciona. Pensando no contexto escolar, podemos afirmar que os preconceitos exteriorizados verbalmente, fisicamente ou em forma de ações excludentes contra a população negra foram e são suscitados, na maioria das vezes, simplesmente pelo fato da cor da pele ou por questões econômicas e até mesmo pelos traços físicos que afastam das relações sociais os sujeitos portadores de direitos e deveres asseverados constitucionalmente. E é na própria escola, a partir da Educação Infantil até a conclusão do Ensino Médio, que o cidadão negro enfrenta ações discriminatórias pelas outras crianças e/ou estudantes da classe ou da escola no geral.

Ao contrário do que é expressado pelo entrevistado $\mathrm{B}$, vejamos a resposta do entrevistado A,

já fui desprezada por ser negra, aí você não sabe o que pesa mais, se é a questão ser negra, por ser gorda, principalmente no meu período de estudante do Ensino Fundamental e Ensino Médio na escola. Infelizmente o local onde se predomina o preconceito ainda é na escola desde o momento de escolher uma duplinha para fazer o trabalho até no dia que você tem que escolher um parceiro pra dançar a quadrilha, (Entrevistado A, 2015). 
Ressalta ainda que,

são cenas que até hoje eu me emociono muito quando eu vejo isso acontecer. Eu não aceito isso né, porque são coisas que marcam a criança pro resto da vida. Hoje eu sou uma adulta, sou bem resolvida com relação a minha cor, não tenho nenhuma vergonha, me assumo enquanto negra (...). Eu estudei e venci, venci vários preconceitos por conta da minha cor. E outro fator que nos acompanha além da cor é a questão de ser pobre. Além de negra, pobre e gorda. Então imagina quanto preconceito sofri quando tinha a idade desses garotos (Entrevistado A, 2015).

Imaginamos quanta dor esta pessoa pode ter sentido e as marcas que ainda pode carregar de seu tempo de estudante em relação às ações excludentes, mesmo tendo evidenciado que venceu os preconceitos contra a cor. Figura ainda em sua fala, que se ser negro é alvo de atitudes preconceituosas, imagine, sendo "negra, pobre e gorda".

Diante dessa realidade, defendemos como extremamente necessário que as unidades educacionais desenvolvam trabalhos referentes a educação das relações étnico-raciais a partir da idade em que as crianças começam a frequentar o universo escolar, pois, a mesma, constitui-se como um dos espaços privilegiados para a convivência de diferentes grupos étnicos, sociais e culturais é, ainda, um lugar oportuno para a reeducação das relações étnicoraciais. É nela que: "impõem aprendizagens entre brancos e negros, trocas de conhecimento, quebra de desconfianças, projeto conjunto para a construção de uma sociedade justa, igual e equânime (BRASIL, 2004, p. 14).

Para tanto, a escola é um dos espaços que deve propiciar momentos de discussão racial para além das questões mitológicas e folclóricas, tornando-se a cada dia um dos espaços de luta contra o racismo, de conquista da cidadania negra (LIMA, 1997). Esta instituição tão valorosa em nosso meio, é o meio mais admissível para o desenvolvimento de ações aguerridas ao racismo contribuindo de forma a salutar para que, o preconceito pela cor da pele, deixe de ser uma constante em nossa sociedade como bem afirmou o entrevistado B.

No entanto, por outro lado, conforme afirma Antonio Flávio Barbosa Moreira e Vera Maria Candau em seu trabalho intitulado Educação escolar e cultura (s): construindo caminhos $^{2}$, há de se falar e reconhecer também os sutis processos de discriminação que permeiam as práticas educacionais em suas diversas dimensões. Para os autores,

as escolas são palcos de manifestações de preconceitos e discriminações de diversos tipos. (...) a cultura escolar tende a não reconhecê-los, já que está impregnada por uma representação padronizadora da igualdade -

\footnotetext{
${ }^{2}$ Disponível em: Educação como exercício de diversidade (Coleção educação para todos; 6) ISSN 2596-2671
} 
"aqui todos são iguais", "todos são tratados da mesma maneira" - e marcada por um caráter monocultural. Preconceitos e diferentes formas de discriminação estão presentes no cotidiano escolar e precisam ser problematizados, desvelados, desnaturalizados. Caso contrário, a escola estará a serviço da reprodução de padrões de conduta reforçadores dos processos discriminadores presentes na sociedade (BRASIL, 2005, p. 48).

A escola tem um papel fundamental tanto para ajudar os estudantes a refletirem sobre tais práticas, como para incentivar a realização de tais práticas no cotidiano escolar ou fora dos espaços escolares; pois, embora a questão discriminatória esteja enraizada nas escolas, afetando, dimensões educativas, está também muito além dos sujeitos que frequentam a escola.

A atenção da comunidade escolar precisa ser dobrada, até porque nem sempre o currículo educacional é explícito. Dificilmente se visualiza as práticas pedagógicas pela leitura de um PPP-Projeto Político Pedagógico de uma instituição. Há muitas ações que estão invisíveis, que não estão escritas, como por exemplo:

o currículo oculto, a dinâmica relacional, as atividades em sala de aula, o material didático, as comemorações e festas, a avaliação, a forma de se lidar com as questões de disciplina, a linguagem oral e escrita (as piadas, os apelidos, os provérbios populares etc.), os comportamentos não-verbais (olhares, gestos etc.) e os jogos e as brincadeiras (BRASIL, 2005, p. 48).

Realmente, o trabalho contra a discriminação racial é intenso. Não é de hoje para amanhã que a problemática será resolvida. É um processo que exige releitura da própria visão de educação, um novo olhar, uma nova ótica, uma sensibilidade diferente (BRASIL, 2005).

É uma situação constrangedora para todos nós brasileiros visto que nossa sociedade, grande parte, isso grande mesmo, a maioria é de descendência afro, advinda da sociedade negra que chegou aqui [no Brasil] como escravo e foi se misturando às outras nações europeias, portuguesa e hoje nós temos aí uma miscigenação muito forte, mas com uma grande quantidade de negros no Brasil, (Entrevistado B, 2015).

Todos nós sabemos que o racismo é muito forte nos dias atuais, mas também cresce o nível de consciência de que o racismo é maléfico e precisa ser combatido, denunciado e eliminado (Sant'Ana, 2005, in Munanga, 2005, p. 45). Para um entrevistado, "não podemos negar que não somos preconceituosos. O branco é, o índio é, o negro é, o pardo é, o amarelo é, todos nós somos preconceituosos. (...) Nós precisamos assumir que somos preconceituosos, mas também devemos assumir ou nos propor a lutar contra isso, (Entrevistado B, 2015)". 
E ainda, por ser constrangedor conforme afirma o entrevistado é que não devemos parar mesmo com o combate, não devemos nos desanimar, pois a cada dia de luta estaremos mais próximos daquilo que pretendemos alcançar, ou seja, tratamento igualitário para todos que, independente da sua cor ou origem fazem parte desta sociedade. Portanto, "o ser negro não é ser diferente dos outros, a diferença é o preconceito" (Entrevistado A, 2015).

Por conseguinte, o que se depreende desse contexto é que, ser negro é diferente sim, mas, apenas na cor da pele, pois jamais se poderá medir a capacidade de alguém tendo como parâmetro a cor de sua pele.

A seguir trazemos mais outro bloco contemplando os resultados dos questionamentos a respeito dos tipos de preconceitos e desrespeitos enfrentados pelos negros na atualidade.

\title{
3.3 Ser negro: o desprezo, o preconceito e desrespeitos enfrentados
}

Vejamos a seguir as ponderações dos entrevistados acerca dessa abordagem. São práticas reais, existentes, ou não? Quem as praticam?

\begin{abstract}
essa questão do negro em nossa sociedade e os desrespeitos que ocorrem em relação ao negro é na verdade uma ignorância da nossa parte quando a gente vê inclusive um negro tratar o outro de negro no termo pejorativo. A gente vê isso, né. Dependendo do status social que ele tem, do cargo que ele tem, do dinheiro que ele tem, tudo isso é motivo pra que ele faça uma certa pejoração do outro que tem o mesmo sangue, a mesma cor, a mesma raça inclusive. Quando eu vejo isso eu fico até envergonhado, (Entrevistado B, 2015).
\end{abstract}

Conforme percebemos, há práticas de racismos e tentativas de invisibilidades não somente por quem tem a cor diferente, mas, também entre pessoas negras,

todos os dias vivenciamos e convivemos com cenas de preconceito, seja ele racial, social ou por opção sexual. O que eu faço quando deparo com uma situação como essa? A minha preocupação maior é com quem sofre o preconceito. Muitos alunos já deixaram de estudar por sofrerem preconceito, por serem discriminados. Então eu me preocupo muito com quem sofre porque com quem pratica você ir discutir com quem é preconceituoso eu tento gerar uma reflexão, eu sempre peço pra pessoa se colocar no lugar da pessoa que ele tá tentando humilhar, (Entrevistado A, 2015).

Eu já sofri bullying, na época a gente nem conhecia por esse nome de bullying né, mas já fui maltratada sim com relação a isso, mas a gente tinha as formas de reagir também. O mais importante de ter sofrido ou não é ter vencido o preconceito na época de vocês e ter mostrado que o negro pode tanto como o branco, como o índio ter o seu lugar na sociedade porque o mais importante é o respeito. (...) o preconceito deve ser combatido através do respeito (Entrevistado B, 2015). 
Os dois entrevistados corroboram dos mesmos sentimentos, afirmam que vários estudantes deixam de frequentar os espaços escolares por sofrerem algum modo de preconceito, por serem discriminados de alguma forma. E a escola é incapaz de perceber tais ocorrências. Em muitos casos, a própria escola denomina isso como vitimismo. A escola crê que estão apenas com sensação de quem está ou foi sujeito a maus-tratos.

Veja a confirmação de um entrevistado: "Em nosso tempo de escola sim, na molecada né, a gente nem leva tanto em consideração porque tá tudo na farra, mas já ocorreu sim. Depois de adulto, da gente entrar na vida do trabalho, na vida acadêmica aí isso não ocorreu mais, (Entrevistado B, 2015).

A escola precisa ser entendida como uma instituição social que influencia na formação e socialização dos sujeitos dela participantes, e por isso, participa de forma decisiva na produção, manutenção ou subversão de padrões de comportamentos, como na constituição da autoestima, na consciência de pertencimento racial, entre outros.

Segundo MUNANGA (2005, p. 15),

alguns professores, por falta de preparo ou por preconceitos neles introjetados, não sabem lançar mão das situações flagrantes de discriminação no espaço escolar e na sala como momento pedagógico privilegiado para discutir a diversidade e conscientizar seus alunos sobre a importância e a riqueza que ela traz à nossa cultura e à nossa identidade nacional.

Deste modo, uma vez evidenciada a importância da comunidade educacional no processo de erradicação de ocorrências preconceituosas no ambiente escolar, é preciso sair do estado de comodidade em que se encontra e dar a largada inicial rumo a superação do preconceito racial.

O próximo bloco de informações está relacionado às oportunidades e inserção do negro no espaço educacional e no mundo do trabalho.

Historicamente sabemos que mesmo diante do fim da escravidão, não houve a inserção do negro na sociedade, ficando para os negros as posições subalternas, e, mal remuneradas. Vejamos a fala do entrevistado B, ao afirmar que são muitas as frentes que o negro sai em desvantagem, "o negro tem uma dificuldade de entrar na escola, e quando entra, de se manter nela. Quando crianças, os pais forçam e são obrigados a ir pra escola. Outros não permitem ir, devido morarem em regiões mais desertas do país sem acesso a escolas, (Entrevistado B, 2015)".

Afirma ainda o entrevistado B que, 
a política é uma área em que os negros têm tido uma dificuldade muito grande de entrar. Raramente você vê um deputado negro, um governador negro, um deputado estadual, um senador negro. Na área judicial, nós tivemos aí o ícone digamos que é o Joaquim Barbosa, mas é só também, não tem outro pelo menos que tenha aparecido até então. Mulher negra então, mulher e negra na política você não vê, no judiciário você também não vê, nos postos executivos das grandes empresas também rarissimamente você vê (Entrevistado B, 2015).

Como se vê, o negro vem ocupando os cargos de menor relevância na sociedade, há uma grande quantidade desempregados, sem escolarização, sem condições de moradia. Importante destacar que em muitos casos, quando um negro consegue uma posição de ascensão e cargos considerados importantes, utilizam da condição de opressor para com os outros. Situação evidenciada na voz de um entrevistado,

Você vê um policial que também é um afrodescendente pegar um negro lá na favela e chega a taca. Ele tá batendo no colega dele de sangue de descendência dele porque ele tem um cargo a mais e aí ele aproveita pra poder espancar o seu condescendente. São situações em que vocês jovens precisam fazer reflexão mesmo, acompanhar os telejornais, acompanhar bem a aula da professora, quando a professora propõe a fazer um trabalho desse é um trabalho muito sério, muito rico e que precisa de muito debate. (Entrevistado B, 2015).

Percebemos que o entrevistado faz um alerta para os estudantes, enfatizando a importância de acompanharem os telejornais, serem leitores das reais situações à sua volta, estarem atentos as aulas e explicações dos professores e serem debatedores de situações vivenciadas nos ambientes escolares.

\subsection{Acesso aos espaços escolares via sistema de cotas}

No brasil, existe a Lei $\mathrm{n}^{\mathrm{o}} 12.711 / 2012$, regulamentada pelo Decreto $\mathrm{n}^{\mathrm{o}} 7.824 / 2012$, que garante a reserva de $50 \%$ das matrículas por curso e turno nas universidades federais e institutos federais de educação, ciência e tecnologia a alunos oriundos integralmente do ensino médio público, em cursos regulares ou da educação de jovens e adultos, conforme definido em seu artigo $1^{\circ}$,

Art. $1^{\circ}$ As instituições federais de educação superior vinculadas ao Ministério da Educação reservarão, em cada concurso seletivo para ingresso nos cursos de graduação, por curso e turno, no mínimo $50 \%$ (cinquenta por cento) de suas vagas para estudantes que tenham cursado integralmente o ensino médio em escolas públicas.

Essa lei tem gerado controvérsias, por um lado, sérias críticas, por outro, fortes defesas. O importante é que as universidades e institutos estão cumprindo e oferecendo as 
vagas para cotistas. Sabemos que não é o bastante, mas, já é um grande avanço à reparação de desigualdades de oportunidades.

Conforme defende um entrevistado, precisamos cada vez mais nos afirmamos enquanto negros, porque é lamentável uma pessoa ter vergonha de usufruir daquilo que é seu direito, "muitas pessoas negras que negam a sua cor, que deixam de usufruir de benefícios como na universidade, como no concurso por ter vergonha de assumir a sua cor, a sua raça, (Entrevistado A, 2015).

Na mesma perspectiva ainda afirma o entrevistado:

Sou a favor das cotas. Oxalá se nós não precisássemos de cotas. Por quê? Porque a cota nos mostra o quanto nos foi renegado no passado um espaço numa universidade, o espaço na vida pública. Não há parlamentares negros. Então quem ocupa o poder? Quem tem o domínio da nação brasileira em termos de poder? São os brancos. E os poucos que conseguem chegar, as cotas mesmo nas universidades é uma conquista de muito tempo de luta. Quando vocês estiverem na idade de ingressar na faculdade, quem sabe as condições sejam mais fáceis. Por que o que acontece hoje em relação as universidades? Mas a realidade hoje é diferente. $O$ aluno com um poder aquisitivo, com uma renda que o pai tem um salário bom, ele estuda o Ensino Fundamental que é o que vocês estão fazendo na escola particular, o Ensino Médio na escola particular, mas quando eles vão fazer a faculdade, eles vão pra faculdade pública. E o que acontece com muitos alunos hoje por exemplo, vão fazer empréstimo, vão pegar auxilio do governo, para estudar numa universidade particular. $O$ que é injusto. Então assim, eu sou a favor das cotas (Entrevistado A, 2015).

Como se vê, a defesa é que a lei de cotas é uma política de benefício para aqueles que ao longo da história foram impedidos de ter as mesmas oportunidades de estudos que os outros, logo, suas chances de concorrer de igual para igual são de fato menores.

Eu fico muito preocupada quando chega a semana do dia 20 de novembro porque aí todo mundo começa a falar bem do negro, seja na mídia televisiva, seja nas redes sociais, todo mundo fala bem no negro é uma coisa assim de se admirar, todo mundo começa a fazer reflexões, mas e nos outros 364 dias do ano, como que esse negro é tratado? (...) Eu procuro trabalhar a partir das oportunidades que vão surgindo durante as aulas. Desde o começo do ano eu estou trabalhando com os meus alunos sobre a imagem do negro no Facebook, no WhatsApp. (...) Quando aparece uma imagem para tirar sarro de alguém, satirizar alguém, qual que é a imagem que aprece lá? É um negro bonito: Não! Geralmente é com o estereótipo feio, com os lábios mais grossos do que nós já temos, com o nariz mais achatado do que o meu. (...) E quando aparece um negro bonito, como que esse negro aparece no Facebook ou no WhatsApp? Ele tem o olho verde, ele tem o cabelo bem cacheadinho, aqueles cachinhos soltos, não é assim que eles aparecem quando ele é bonito? Então ele aprece já o estereótipo, com características do branco já para amenizar. Olha ela é neguinha, tem o cabelo enrolado, mas ela tem o olho lindo. Então assim, o que que salva ela? O olho. (...) Não tem um brasileiro que 
pode falar, há eu não tenho nada de negro no meu sangue, (Entrevistado A, 2015).

São várias as possibilidades de trabalhar essa temática em ambientes escolares, é preciso respeitar as diferenças, pois isso é fundamental, é preciso que haja respeito recíproco. Agindo assim é possível que se terá no amanhã, uma sociedade mais justa, igualitária, humanizada.

Pois, somente quando a sociedade compreender que é pelo respeito mútuo às diferenças, é pela valorização do sujeito enquanto ser humano, que a cor deixará de ser preocupação, impedimento de alcance ao trabalho e de entradas em universidades públicas.

Deste modo, a expectativa é que um dia esse país, consiga ver e tratar com respeito, e oportunidades, o negro, o indígena, o branco, o asiático, ou outro, qualquer que seja sua origem, como ser humano, além de reconhecer que tais diferenças enriquecem a cultura do país.

\section{Considerações finais}

"Se a educação sozinha não transforma a sociedade, sem ela tão pouco a sociedade muda". Com esta frase tão autêntica de Paulo Freire faremos algumas considerações, não as finais, pois entendemos que o assunto abordado neste artigo merece mais aprofundamento, pois é objeto de estudo para todos os dias na nossa sociedade.

Por ser um contexto atual é que as unidades educacionais não devem paralisar seus trabalhos educativos a fim de combater a perpetuação de atitudes preconceituosas contra os afrodescendentes que em muitas das vezes se iniciam na Educação Infantil. Mesmo que as vezes os enfoques sejam os mais simples, todavia é necessário a continuidade de um trabalho que vise formar cidadãos menos preconceituosos e mais respeitosos às diferenças sejam elas quais forem.

Muito além disso, também é função social das escolas o trabalho em sala de aula com aquilo que se percebe imprescindível para toda a sociedade. Portanto, não se pode negligenciar diante de situações que desrespeitam a diversidade e, aqui, em especial, a diversidade étnico-racial, que a partir de um trabalho pedagógico educativo pode ser prevenido e, em muitos casos, evitar até a morte de alguém.

Os estudos realizados no decorrer dessa pesquisa, mostraram que o melhor meio para se trabalhar o respeito a diversidade étnico-racial é através das escolas. Neste trabalho é 
primordial o conhecimento por parte dos educadores, dinamicidade, ludicidade, bem como abordagens atrativas, reflexivas e enriquecedoras de conhecimentos aos estudantes, pois serão estes estudantes frutos do trabalho escolar, que irá combater ou, caso contrário, reproduzir as desigualdades sociais.

\section{Referências}

BRASIL. Contribuições para Implementação da Lei 10.639/2003. Grupo de Trabalho Interministerial Instituído por Meio da Portaria Interministerial MEC/MJ/SEPPIR No 605 de 20 de Maio de 2008.

BRASIL. Constituição Federal da República de 1988. Disponível em: http://www.planalto.gov.br/ccivil_03/constituicao/constituicao.htm. Acesso em: 19 de Maio de 2019.

BRASIL. Decreto 7.824, de 11 de outubro de 2012. Disponível em: http://www.planalto.gov.br/ccivil_03/_ato2011-2014/2012/decreto/d7824.htm. Acesso em: 19 de Maio de 2019.

BRASIL. Diretrizes Curriculares Nacionais para educação das relações étnico-raciais e para o ensino da história e da cultura afro-brasileira. Brasília, DF: MEC/SEF, 2004.

BRASIL. Educação como exercício de diversidade (Coleção educação para todos; 6). Brasília: UNESCO, MEC, ANPEd, 2005.

BRASIL. Lei 7.716, de 05 de Janeiro de 1989. Disponível em: http://www.planalto.gov.br/ccivil_03/leis/17716.htm. Acesso em: 19 de Maio de 2019.

BRASIL. Lei no 10.639, de 09 de Janeiro de 2003. Disponível em: http://www.planalto.gov.br/ccivil_03/leis/2003/110.639.htm. Acesso em: 19 de Maio de 2019.

BRASIL. Lei 12.711, de 29 de agosto de 2012. Disponível em: http://www.planalto.gov.br/ccivil_03/_ato2011-2014/2012/lei/112711.htm. Acesso em: 19 de Maio de 2019.

BRASIL. Lei 12.735, de 30 de novembro de 2012. Disponível em: http://www.planalto.gov.br/ccivil_03/_Ato2011-2014/2012/Lei/L12735.htm. Acesso em: 19 de Maio de 2019.

BRASIL. Lei 12.990, de 09 de junho de 2014. Disponível em: http://www.planalto.gov.br/CCIVIL_03/_Ato2011-2014/2014/Lei/L12990.htm. Acesso em: 19 de Maio de 2019.

CAVALLEIRO, Eliane. Do Silêncio do lar, ao silêncio escolar: racismo, preconceito e discriminação na educação infantil. São Paulo: Contexto, 2000. 
DICIONÁRIO online. Disponível em: https://www.dicio.com.br/preconceito/. Acesso em: 24 de Julho de 2019.

FERREIRA, Lúcia de Fátima Guerra. PROMOÇÃO DA EQUIDADE E RESPEITO ÀS DIFERENÇAS. In: CALISSI, Luciana; SILVEIRA, Rosa Maria Godoy (Org.). O ECA nas Escolas: Perspectivas Interdisciplinares. João Pessoa: Editora Universitária da UFPB, 2013. p. 54-64.

GIL, Antônio Carlos. Como Elaborar Projetos de Pesquisa. 5a Edição. São Paulo: Atlas, 2002.

GOMES, Nilma Lino. Diversidade étnico-racial e educação no contexto brasileiro: algumas reflexões. In: GOMES, Nilma Lino (Org.). Um olhar além das fronteiras: educação e relações raciais. Belo Horizonte: Autêntica, 2007, p. 97-109.

LAKATOS, Eva Maria. Fundamentos de metodologia científica. Marina de Andrade Marconi, Eva Maria Lakatos. - 5. ed. - São Paulo: Atlas 2003.

LIMA, I. C. Ações educacionais em Santa Catarina. In: BARBOSA, L. M. de A.; SILVA, P. B. G. e. Pensamento negro em educação no Brasil. São Carlos: EDUFSCar, 1997.

LUDKE, Menga \& ANDRÉ, Marli E.D.A. Pesquisa em educação: abordagens qualitativas. São Paulo, Editora Pedagógica e Universitária, 1986.

MUNANGA, Kabengele (org.) - Superando o Racismo na Escola, $2^{a}$ edição. Ministério da Educação, Secretaria da Educação e Diversidade, 2005.

SANTOS, Ivone Aparecida. Educação para a diversidade: uma prática a ser construída na Educação Básica. Universidade Estadual do Norte do Paraná - Campus de Cornélio Procópio. Caderno Temático - apresentado ao Programa de Desenvolvimento Educacional do Estado do Paraná - PDE, 2008. 